\title{
MECHANISMS OF RECRUITMENT FOR THE RETRIEVAL OF FOOD IN AMITERMES EVUNCIFER SILVESTRI (ISOPTERA:TERMITIDAE:TERMITINAE)
}

\author{
S. L. Omo Malaka ${ }^{1}$ and R. H. Leuthold ${ }^{2}$ \\ 'Department of Biological Sciences, University of Lagos, Akoka, Lagos, Nigeria and \\ ${ }^{2}$ Universität Bern, Zoologisches Institute, Abteilung for Zoophysiologie, CH-3012 Bern, Erlachstrasse 9a, \\ Switzerland
}

(Received 20 February 1986; revised 9 June 1986)

\begin{abstract}
The study revealed that there was quantitative recruitment in colonies of Amitermes evuncifer, whenever food was discovered by the scouting foragers. Discovered food stimulated the termites to accelerate their running speed, to and from the food source. Increased trail-laying activity, accelerated movement and carrying of food by the returning workers facilitated recruitment of other confederates from their nest. These activities equally directed the recruited termites to the food source.

Amitermes evuncifer was observed to regulate traffic in relation to newly discovered food source. The results showed that there was rapid communication between the termites of food source within 3-4 min. It was further observed that the trail to newly found food source did not become dominant over the trail to the already existing food source. The results showed clearly the effect of food on vital activities of termites.
\end{abstract}

Key Words: Recruitment, Amitermes evuncifer, food, arena, traffic, trail

Résumé-Cette étude montre qu'il y a un accroissement numérique des colonies d'Amitermes evuncifer chaque fois que les fourrageurs découvrent des sources d'alimentation. De telles sources incitent les termites a forcer la vitésse de déplacements entre le point de départ et les sources d'alimentation. Le depôt de traces de pheromone les deplacements entre le point de départ et les sources d'alimentation et la transportation des vivres par les ouvriers facilitent le recrutement des confédères de leur nid. Les mêmes activites servent aussi à diriger les termites nouvellement recrutés vers les sources d'alimentation.

On a pu observer que l'Amitermes evuncifer régit le trafic vers des sources d'alimentation nouvellement découvertes. Les données montrent que les renseignements sur la decouverte des sources d'alimentation sont transmis parti les termites en trois ou quatre minutes environi après la découverte. On a noté également que les traces menant à une source d'alimentation nouvellement découverte n'a aucun avantage sur une source qui préexistat. Les données démontrent clairement les effets qu'ont les vivres sur les activités essentielles des termites.

\section{INTRODUCTION}

Amitermes evuncifer Silvestri is a common moundbuilding termite pest species in the humid forest zones and Southern Guinea Savannah in West Africa. In Nigeria, it causes considerable damage to buildings and wooden structures, as well as to food crops, ornamental shade-providing trees and to forestry. Although some study has been carried out on the general biology of this termite (Sands, 1962, 1971; Malaka, 1973, 1977a, b, c, 1980a, b, 1983), not much is known concerning its exploratory behaviour.

It is a well known fact that the social insects (particularly ants and termites) have evolved many ingenious mechanisms which serve to assemble confederates (mostly workers and soldiers) for joint efforts in food retrieval and nest construction. The recruitment of nest mates to the food is achieved by a mechanism of communication that consists of a chain of several releasing stimuli, such as scent trail, tactile and vibrational stimulation. Traniello (1981) found that the nasute soldiers of the neotropical termite Nasutitermes costalis function as scouts by exploring new terrain for food in advance of the worker caste and regulate foraging activity by laying trails, composed of sternal gland pheromone. Wilson (1962) and Blum and Ross (1965) proved that the trail pheromone releases searching behaviour and lead the ants, Solenopsis saevissima and Tetramorium guineense to the bait. Jaffe and Howse (1979), working with the ant, Atta cephalotes concluded that the number of ants recruited to a food source depended on the quality of the food and on the duration of starvation of the colony, and is related to the concentration of trail pheromone on the trail, but not to the number of ants initially returning to the nest from the food source.

Szlep-Fessel (1970) found that highly excited recruiters of the ant Pheidole, arriving at the nest, perform, in addition to trail laying, a motor recruitment display, comprising running, accelerated antennal beatings and body oscillations. Leuthold (1968) found that two active patterns of recruitment to the food performed by food finder ants of Crematogaster ashmeadi are, trail-laying directed at the colony as a whole, and the alerting of individual nest mates.

This study was aimed at explaining the mechanisms of communication for the retrieval of food in 
Amitermes evuncifer Silvestri. This was to understand the strategy of this pest for food exploration and retrieval. Traffic orientation in relation to food was looked into in order to understand if the food source has any specific directional effect on the activities and/or movements of the pest. Traffic regulation in relation to newly supplied food was looked into in order to ascertain among others the speed of communication of newly found food source, and the permanence as well as the overall effect of the chemical message. The comprehensive analysis of traffic development was carried out in relation to food supply in order to understand in some detail the regulatory mechanisms in recruitment activities.

\section{MATERIALS AND METHODS}

Basic set up for controlled foraging in the laboratory

In this study, laboratory colonies of $A$. evuncifer, which were normally collected from the central parts of field mounds at different times from the University of Lagos, were used. Before the experiments the mounds had been kept in the laboratory from 2 to 8 months, at temperatures of $28 \pm 2{ }^{\circ} \mathrm{C}$ and of $60 \%$ $\pm 10 \%$ r.h. The basic set up for the experiment was as follows. Two arenas, each a plastic Petri dish with covers $($ dia $=7.5 \mathrm{~cm}$, depth $=3 \mathrm{~cm})$, were provided. Each Petri dish was provided with a coating of wet fine silt at the base. This was allowed to harden (dry) in 2 to $3 \mathrm{hr}$. This prepared surface was conveniently moved on by the termites.

The set up was very well organized in order to facilitate detailed observation as well as prevent vibrational disturbance in the colony during the recruitment experiments. On each of the covers of the two Petri dishes (arenas), was drilled two tiny holes, fine enough to allow fine nylon thread to pass through. The ends of these two thread pieces inside the covers were tied to small office pins, cut in half. These tied half pins were pinned to a tuber of yam piece $(15 \times 10 \times 5 \mathrm{~mm})$ and a plastic cork of equivalent size, respectively. The ends of the two thread pieces lying outside the Petri dish covers were again tied to two halves of office pins, respectively. These were in turn pinned to two fairly large sizeable plastic corks (weights), which were used as weights for suspension, by swinging the fine nylon thread over a raised wooden bar, so that when these covers were placed over the arenas, the food and plastic pieces were firmly fixed (or attached) to the inner side of the arena covers for the first part of the experiment (see Fig. 1). In this arrangement, the food and the plastic did not come into contact with the floor of the arena. From preliminary observations, it was also found that neither the odour of the food (yam), nor of the plastic, when attached to the arena covers, had any influence on termite recruitment.

For the observation area (Fig. 2,) a Y-maze was constructed by grooving $(3.5 \mathrm{~mm}$ in width) a $2 \mathrm{~cm}$ wide perspex sheet, and cutting out three pieces (each piece $2.5 \mathrm{~cm}$ long). With these grooved perspex pieces, the Y-maze was constructed by the use of a special perspex glue. The Y-maze was fixed to a triangular perspex sheet. Another transparent triangular perspex sheet of the same size as the first was placed on top to cover the Y-maze, to enable the observation of termites in the $\mathrm{Y}$-maze through the video camera during the experiment. During the experiment, the nest was attached to the base (stem) of the Y-channel, whose two arms were connected to the two silt-coated arenas (see Fig. 1). Termite activities (frequencies of movement) were observed from the Y-channel, by video transmission. Before the experiment, termites were allowed to acclimatize by allowing them to continue their foraging undisturbed for about $1 \mathrm{hr}$, while casual observation was made through the video monitor. After this 1-hr observation, the video machines were switched on for recording while observations continued at intervals. The initial recording was allowed to continue for $90 \mathrm{~min}$. At the end of this time food was lowered to the apparently less visited arena (either B or C arena as seen from casual observations at intervals), while plastic was lowered to the apparently more visited arena by the termites (either $\mathrm{B}$ or $\mathrm{C}$ arena). The recording was again allowed to continue for another period of $90 \mathrm{~min}$. On the whole, video recording was continuous for a total period of $180 \mathrm{~min}$ after which recording was stopped. At the end of the experiment, by playing back the video tapes, the following assessments were carried out. Per minute counts of (a) termite traffic between the nest and the (two) arenas, (b) termites entering either $\mathrm{B}$ or $\mathrm{C}$ tubes (to the corresponding $\mathbf{B}$ and $\mathbf{C}$ arenas). This experiment was replicated six times.

\section{Testing of trails laid to soil and food arenas}

Trails laid to two soil arenas. In this experiment, a Y-tube was connected from an artificial nest of $A$. evuncifer to two soil arenas (b and c). Two trail collecting bridges (see Fig. 3) containing trail collecting paper slips were connected to $\mathrm{b}$ and $\mathrm{c}$ channels, respectively. Trails were collected for $1 \mathrm{hr}$ each time, and tested for trail strength in a comparative position (Malaka, unpublished material). The experiment was replicated 10 times.

Experiment on comprehensive analysis of traffic development in relation to food supply using double-bridge and construction of double-bridge

For this construction a perspex piece $(18 \times 8 \mathrm{~cm})$ was cut out to act as the base of the double-bridge. Each of the two legs of the bridge was a piece of a square perspex rod (cross-section $=1 \mathrm{~cm}^{2}$ ), $6 \mathrm{~cm}$ long. From one of the ends of each of the two square perspex rods was drilled a hole (about $5 \mathrm{~mm}$ in dia). Before drilling this hole, a gap of about $5 \mathrm{~mm}$ was allowed from the free end of the rod. After leaving a gap of $3 \mathrm{~mm}$, another hole of similar dimensions was drilled below the first hole. The two legs of the bridge were glued to two positions of a marked longitudinal line running along the middle of the base (perspex piece). The space between the two legs was $6 \mathrm{~cm}$ long (see Fig. 4). Three very smooth small wooden pieces ( $3 \mathrm{~mm}$ thick and $4 \mathrm{~mm}$ wide by $6 \mathrm{~cm}$ long) were glued horizontally to the two legs of the bridge as follows (see Fig. 4):

(a) Upper wooden piece was glued horizontally, exactly against the roofs of the two top-holes of the two legs facing each other exactly. 


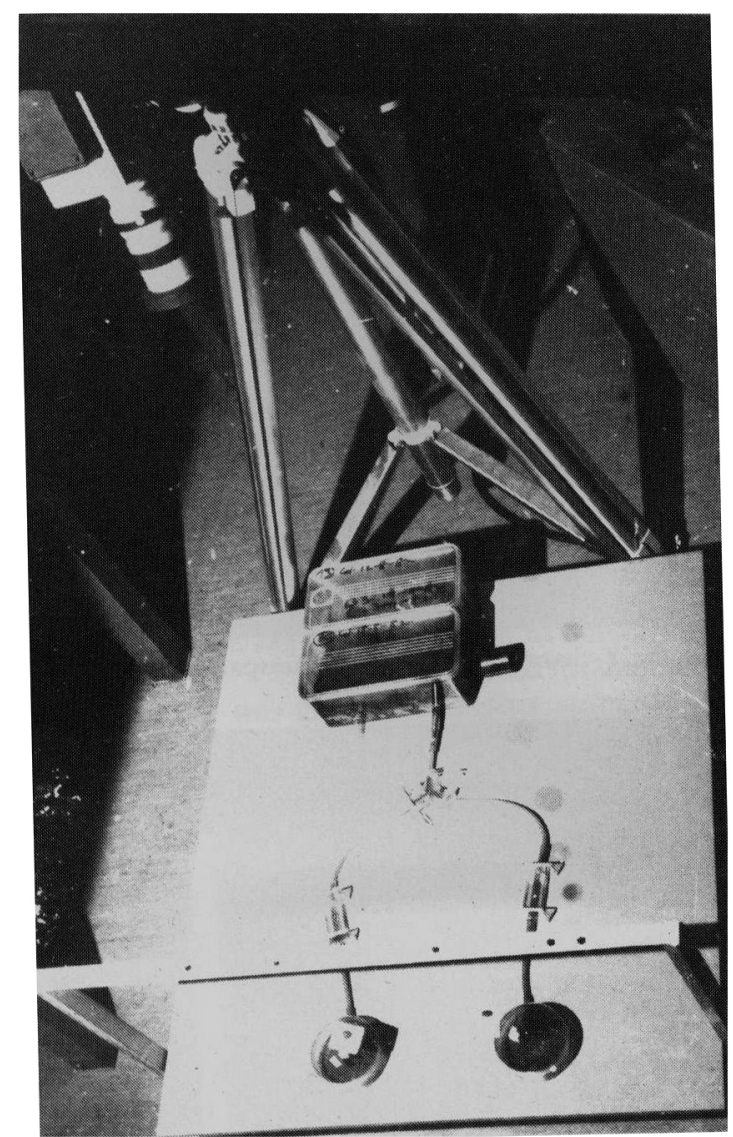

Fig. 1. Set up for the recruitment experiment showing also part of the video camera set to focus termite activities for recording.

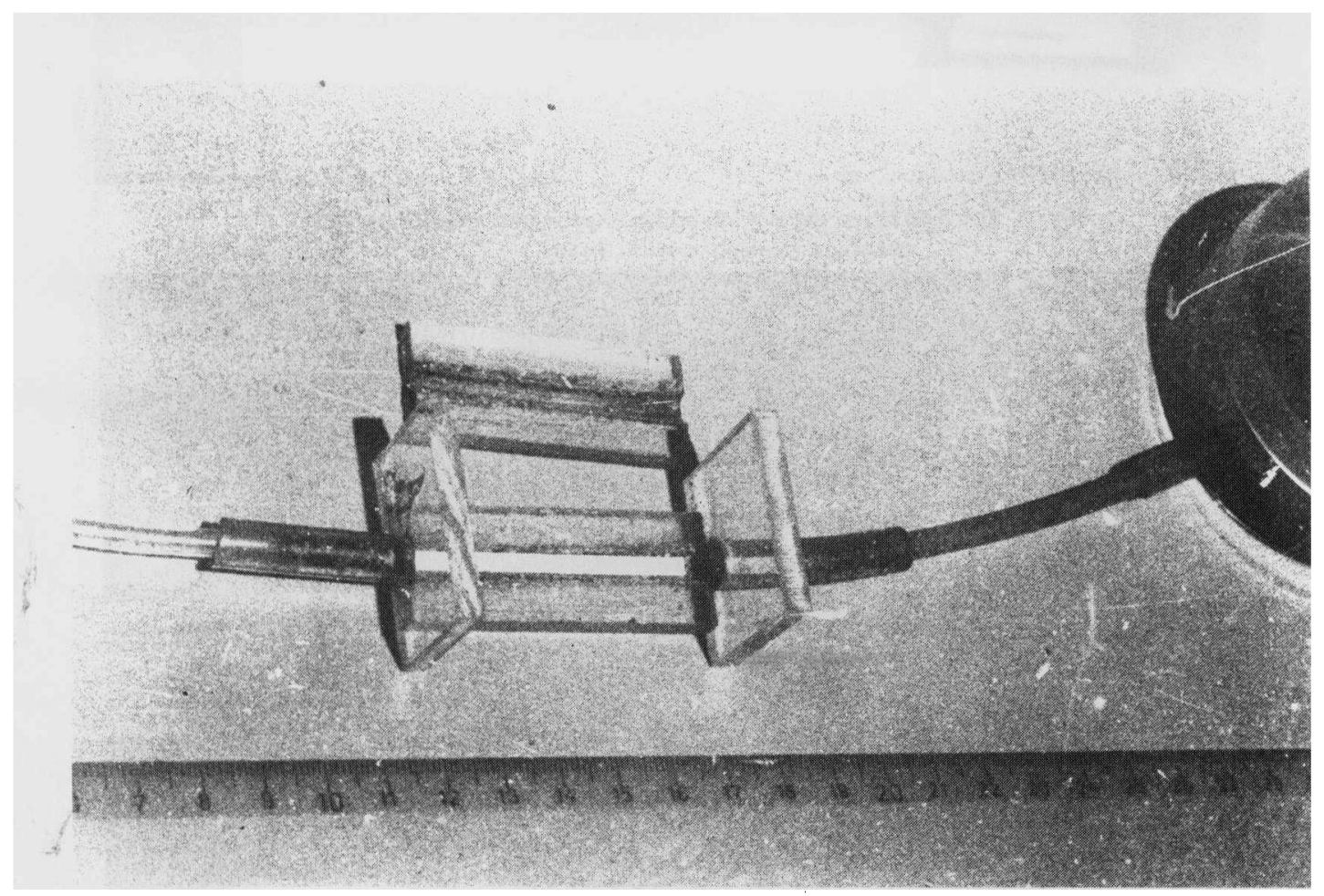




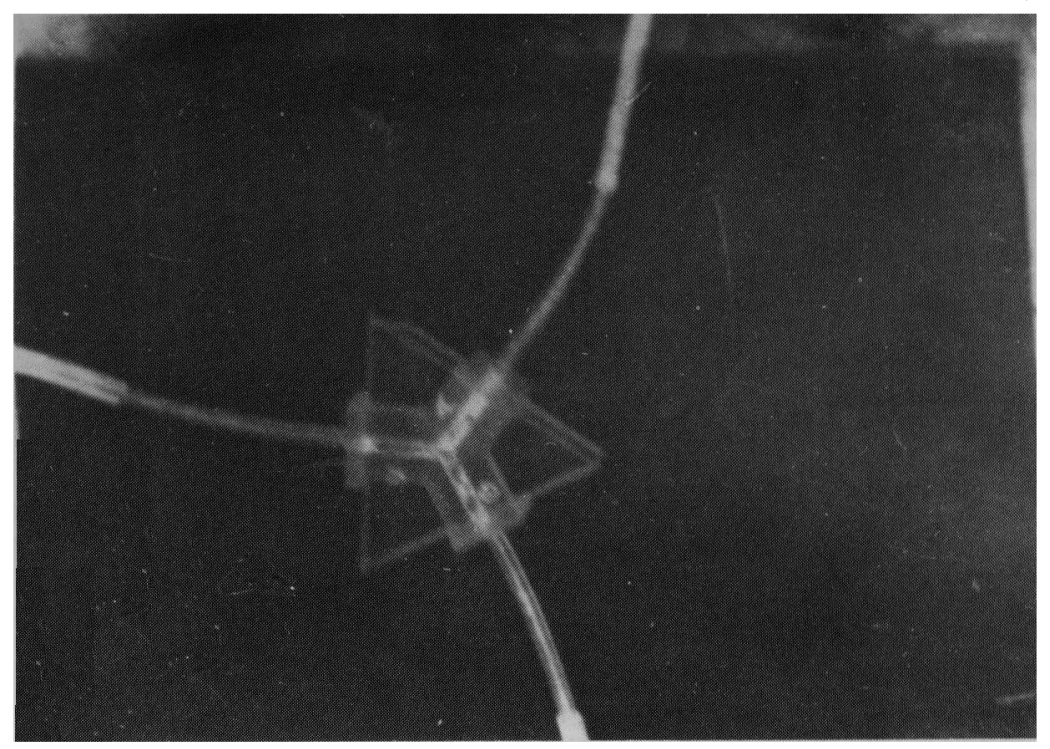

Fig. 2. A set up displaying the Y-channel (covered with transparent perspex) used as observation arena.

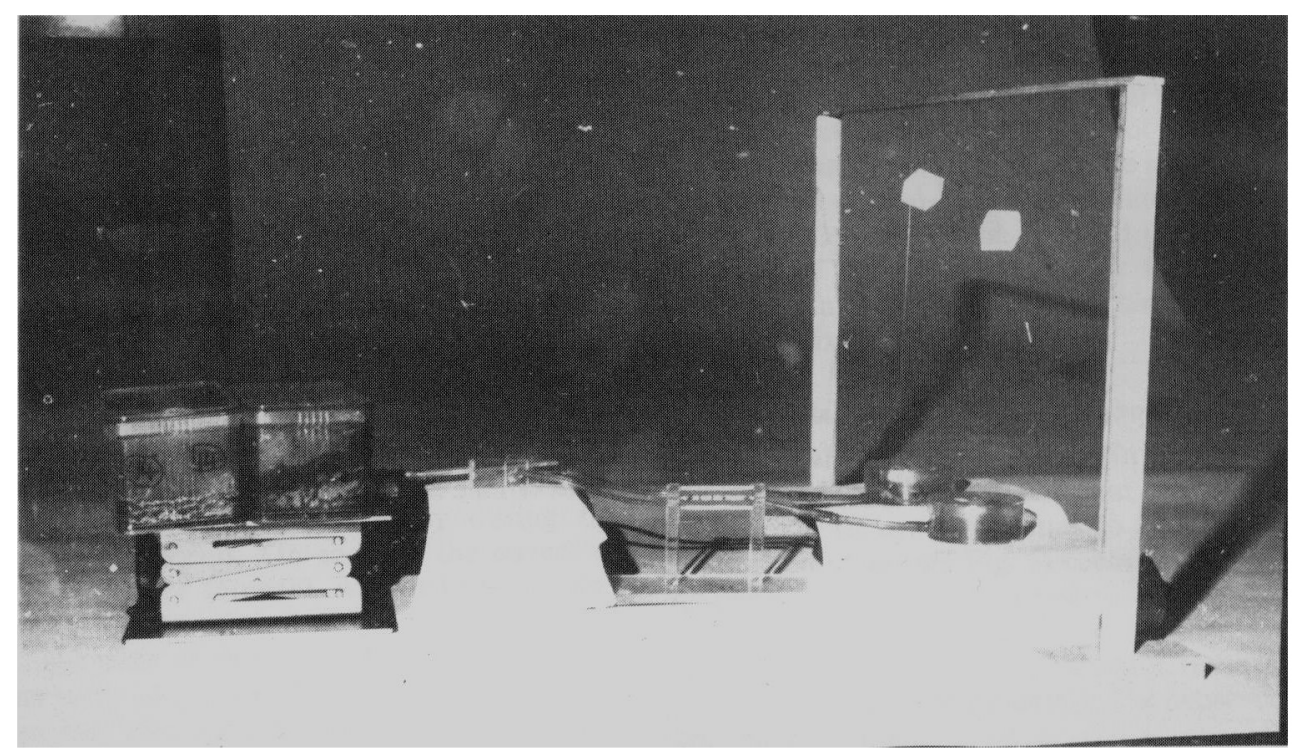

Fig. 5. Demonstrating the double-bridge experiment with A. evuncifer.

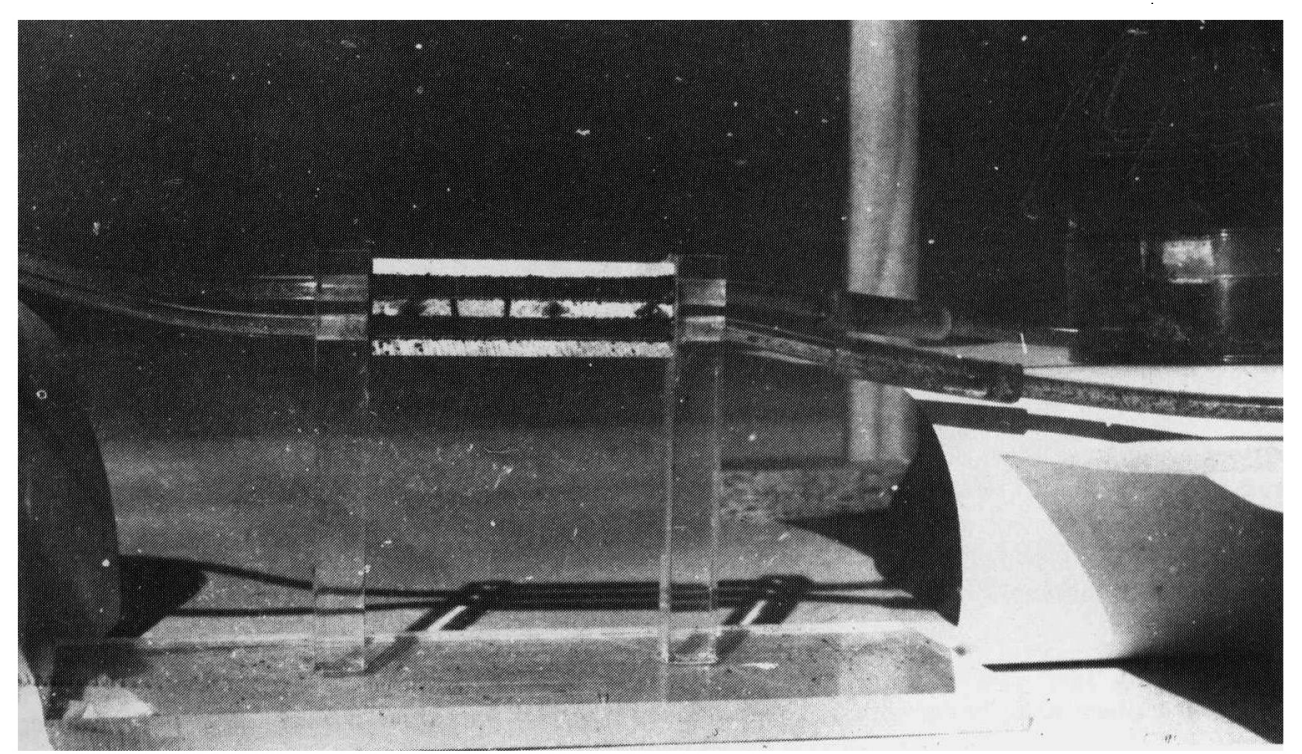

Fig. 6. Set up showing the double-bridge. 


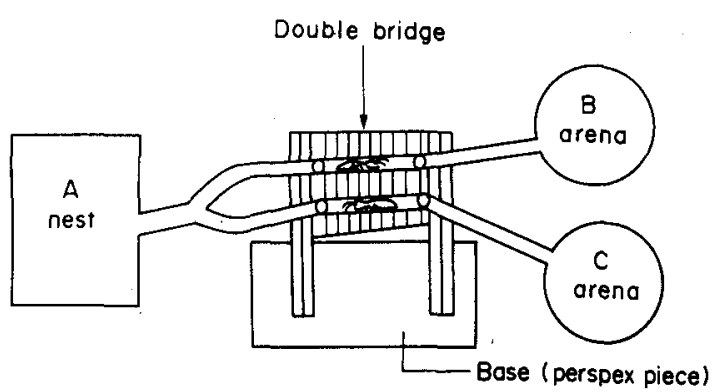

Fig. 4. Double-bridge experiment set up to study the regulatory or appetitive behaviour of Amitermes evuncifer foraging between nest and two different arenas (B and C) with and without food.

(b) The middle piece was glued parallel to the upper piece and fitting exactly the space between the upper hole and the lower hole.

(c) The third and lowest wooden piece was glued horizontally against the lower edge of the second (lower) hole, and lies parallel to the upper and middle pieces.

By the use of a perspex tube, a perspex Y-channel and sizeable rubber tubing, one end of the doublebridge was connected to the laboratory nest (A) of Amitermes evuncifer. The two branches of the Ychannel were connected to the upper and lower holes. Also, by the use of rubber tubing the other end of the bridge was connected to the two arenas (B and C; see Figs 4-5). The upper hole was connected to arena $B$, and the lower to arena $C$. The distance between the nest and the bridge was $25 \mathrm{~cm}$, and the distance from the bridge to the two arenas was $10 \mathrm{~cm}$ each. It must be stated here that the arrangement whereby one 'bridge' was constructed above the other had no adverse effect on the experimental termites. The termites moved undisturbed as in any other recruitment experiment without the use of a double bridge. The arrangement also allowed for detailed observation of the activities of the moving termites (Fig. 7).

By the use of tacki-wax, two sizeable rectangular thin glass slides each exactly $6 \mathrm{~cm}$ long were attached to the two free longitudinal surfaces of the bridge. This was to prevent the termites from falling off or escaping during the experiment.

Before the experiment the termites were allowed to run freely in the set up and food was attached to the inner surface of each of the two covers of the two arenas.

Recording with the video machines then started first to the two soil arenas and continued for $25 \mathrm{~min}$. At the end of this time (i.e. after $25 \mathrm{~min}$ ) food was lowered to one of the two arenas (say B). Recording continued for another $25 \mathrm{~min}$. At the end of this time, recording stopped temporarily, without disturbing the experiment. The time of $5 \mathrm{~min}$ was allowed to change the tapes. Recording to the previous situation (i.e. soil in $\mathrm{C}$ and food in B), continued for another $25 \mathrm{~min}$. At the end of this time, and without stopping the tape and without any disturbance, food was lowered to the second arena (arena $C$ ), and concurrently, food was raised from the arena B. Recording continued again for $25 \mathrm{~min}$. The experiment was then replicated six times. The following analyses were carried out:

(a) Number of termites (worker only) laying trail (TL) to and from the arenas, before and after food supply.

(b) Number of termites (workers only) not laying trails (NTL) to and from the arenas, before and after food supply.

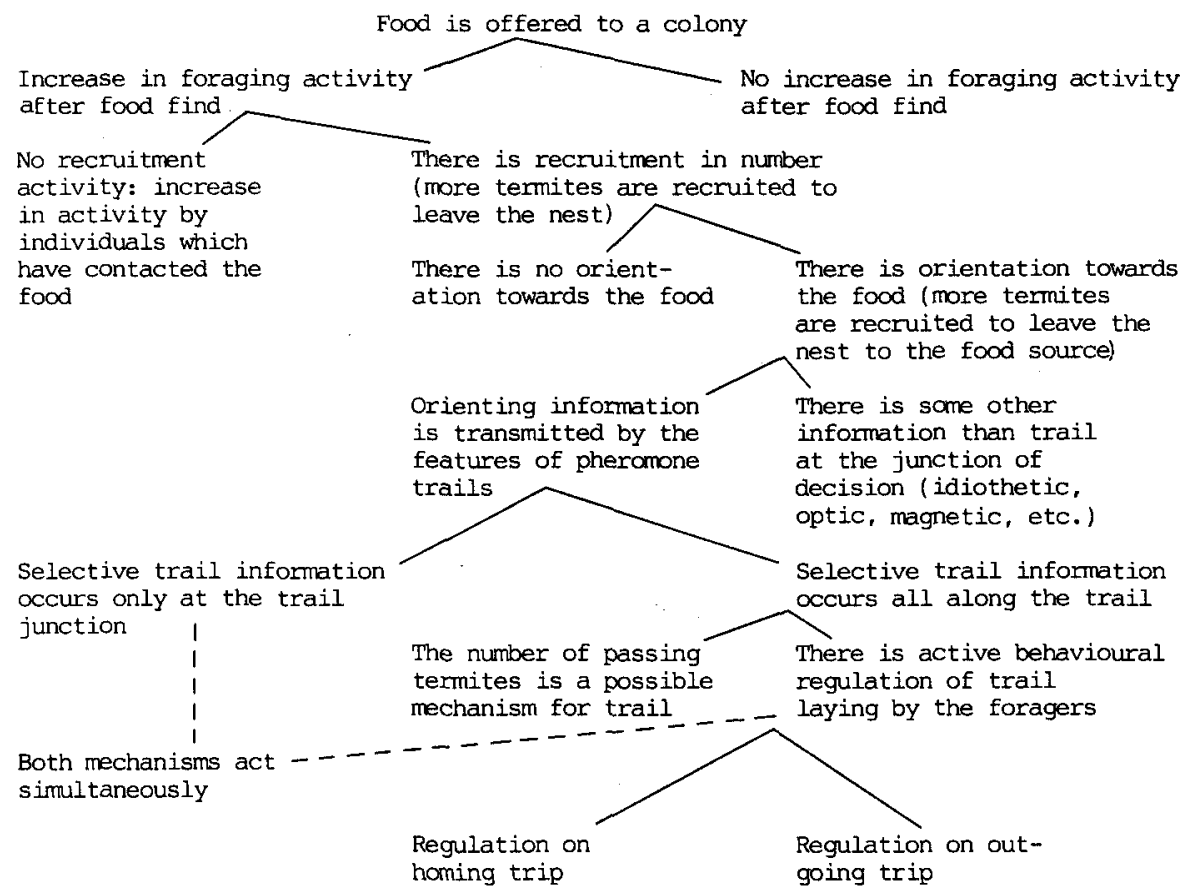

Fig. 7. Flow diagram showing the thinkable mechanism in social food recovery. 


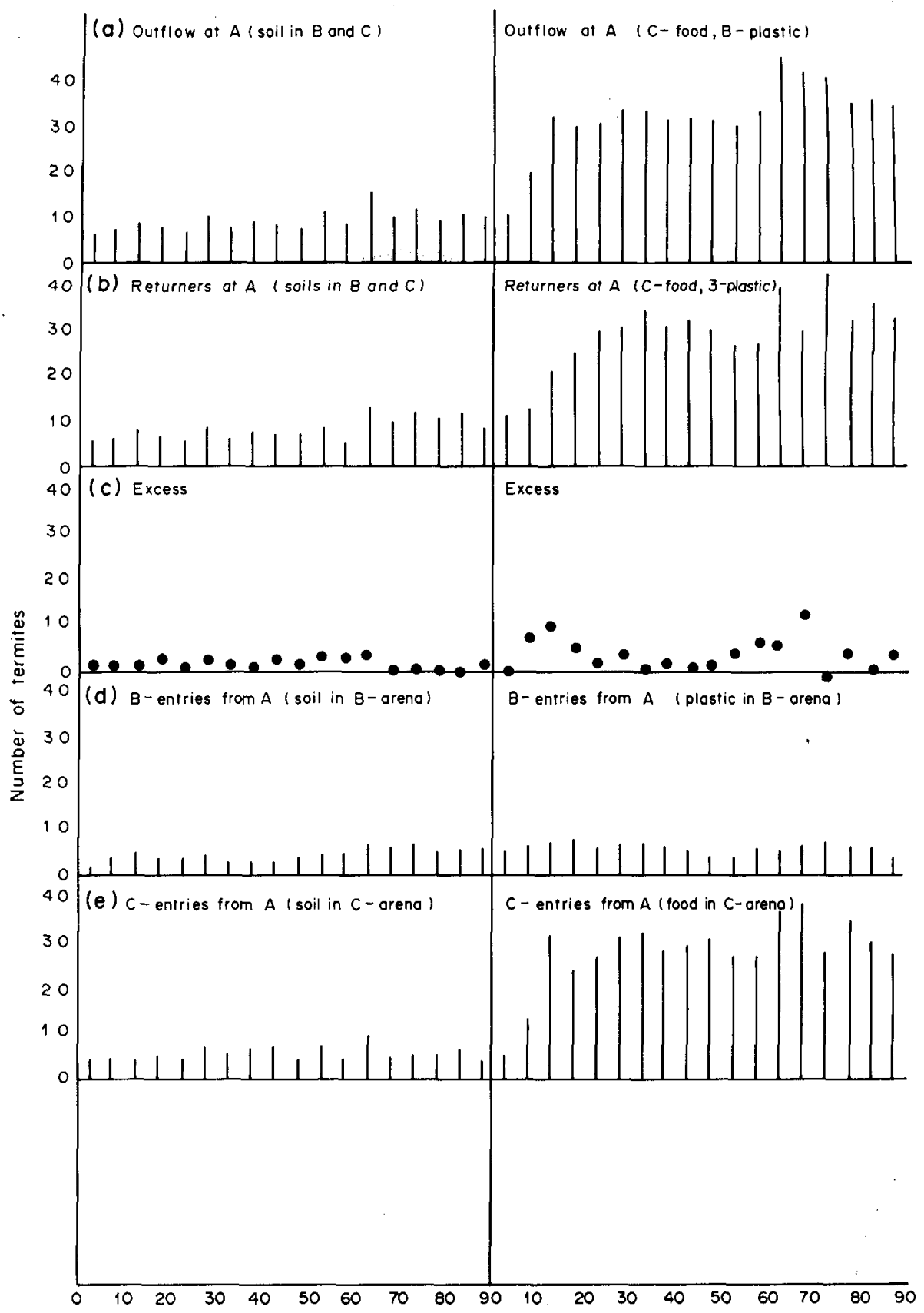

Fig. 8. (a) Results from recruitment experiment, showing the number of termites moving from nest to arena, before and after food supply to one of the two arenas. (b) Results from recruitment experiment, showing the number of termites returning to the nest (from the arena), before and after food supply to one arena. (c) Results from recruitment experiment showing the difference (excess) between outgoers from the nest and returners, before and after food supply to one of the two arenas. (d) Results from recruitment experiment showing termites orientation (entries) of arena B, before and after plastic supply to arena B. (e) Results from recruitment experiment showing termite orientation (entries) to arena $\mathrm{C}$, before and after food supply to arena $C$.

(c) Number of termites carrying mound materials to and from the arenas, before and after food supply.

(d) Number of termites carrying food from the food arena after food supply.

(e) Speed of termites to and from the arenas before and after food supply.

\section{RECRUITMENT OF TERMITES FROM THE NEST DESCRIPTION OF WALKING BEHAVIOUR IN A NON-FOOD SITUATION}

At the beginning of the recruitment experiment when neither food nor plastic was added to either B or $\mathrm{C}$ arena, the termite traffic (outflowers and returners) in the A arm of the Y-channel was low (see 
Fig. $8 \mathrm{a}$ and b). Also the movement of termites to and from the nest was observed to be slow. Despite their slow motion at this time, majority of the termites made several stops lasting from a few seconds to even minutes at the side of the channel (i.e. channel A), before continuing their journey to and from the nest. The movements of the termites can be rightly described as sluggish.

\section{DESCRIPTION OF WALKING BEHAVIOUR AFTER} FOOD FIND: INCREASE OF ACTIVITY AND NUMBER

As soon as food (yam) and plastic were introduced in the two arenas, respectively, different activities were observed. The first thing to be observed was the relatively high speed of the returning termites, followed by the high speed of outflowers and consequently the traffic increased (see Fig. 8a and b). More termites performed oscillatory movements mostly by the returners. From these results, it was quite clear that the increase in foraging activity in the colony was related to the introduction of food. The results also demonstrated that the increased traffic was not merely caused by increase in running activity of the experienced foragers. This meant that more termites were recruited to leave the nest, than the number of termites returning to the nest. In fact there was an excess peak of outflowing termites (from the nest) which was not compensated by a negative peak (of returners to the nest; see Fig. 8c). From these results, it has been possible to demonstrate that recruitment activities occur in the colony. This is a very notable fact which has never been proven for this species of termites. This finding leads to many more interesting investigations with these termites. It has gone a long way to tell us about food retrieval by Amitermes evuncifer. This shows that scouts of Amitermes evuncifer communicate food information to nest mates which in turn are recruited to the food site for efficient food retrieval and utilization. Further observations and experiments will show how these processes are systematically accomplished.

\section{Orientation towards the food source}

At the first part of the experiment (see Fig. 8d and e) when the two arenas $b$ and $c$ contained only fine soil (silt) coating, the entries into the two arms (b and c) of the Y-channel were evidently very low. It was quite clear that the ratio of traffic on both arms (b and c) of the Y-channel was comparable. After $90 \mathrm{~min}$ when food and plastic were added to either B or C, respectively, different results were observed (see Fig. 8d and e). The ratio of traffic changed towards the food side. Thus, in addition to activity increase, there was directional effect by the food. There was therefore orientation towards the food arena. This conclusion still implied the possibility that the food finders have learnt the position of food and, once experienced they selected the left-right decision according to individual learning. This assumption will be further clarified by the following experiments on trail tests to food and plastic arena.

\section{Testing of trails laid to food and soil arenas}

Results of trail tests laid to soil and food arenas. The results of the two sets of experiments, as illustrated in

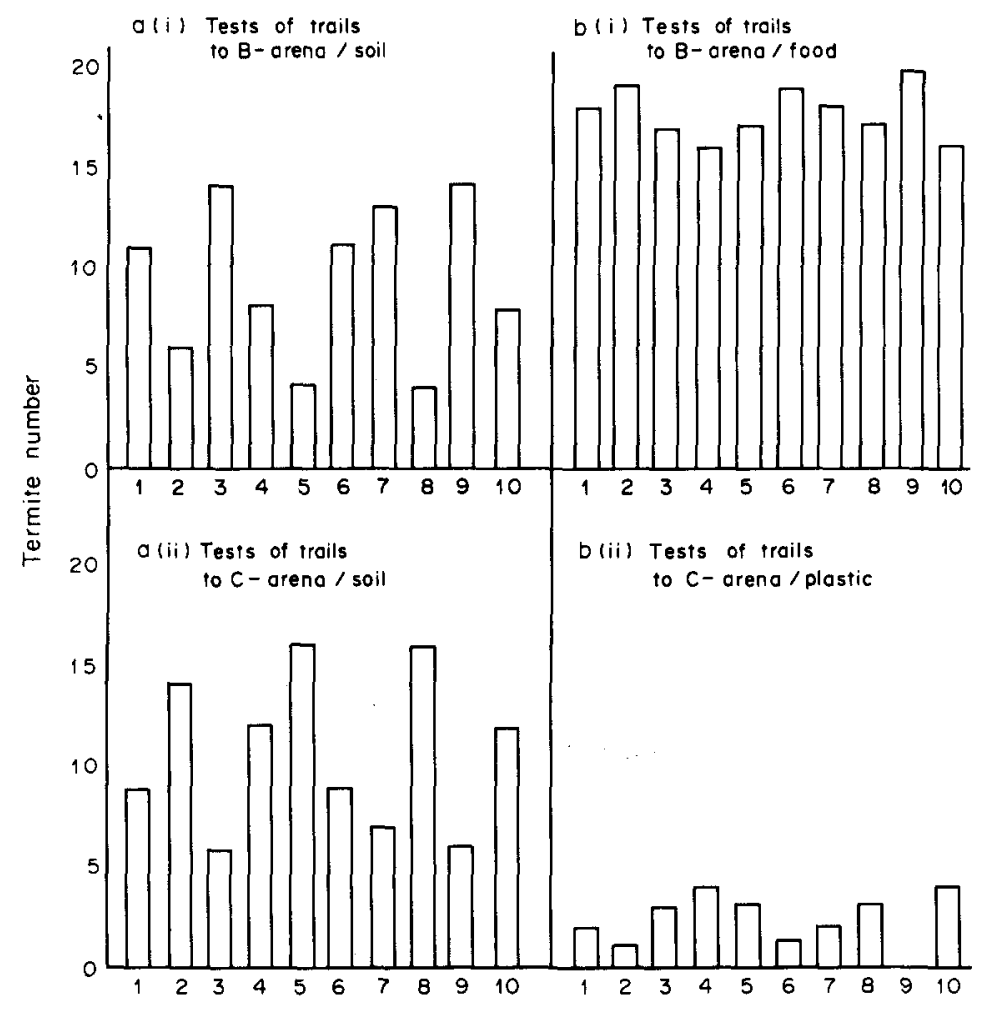

Fig. 9. Histograms summarizing the results of bioassays of natural trails laid between nest and soil/soil

[a(i) and a(ii)] arena and between nest and food/plastic arenas [b(i) and b(ii)]. 


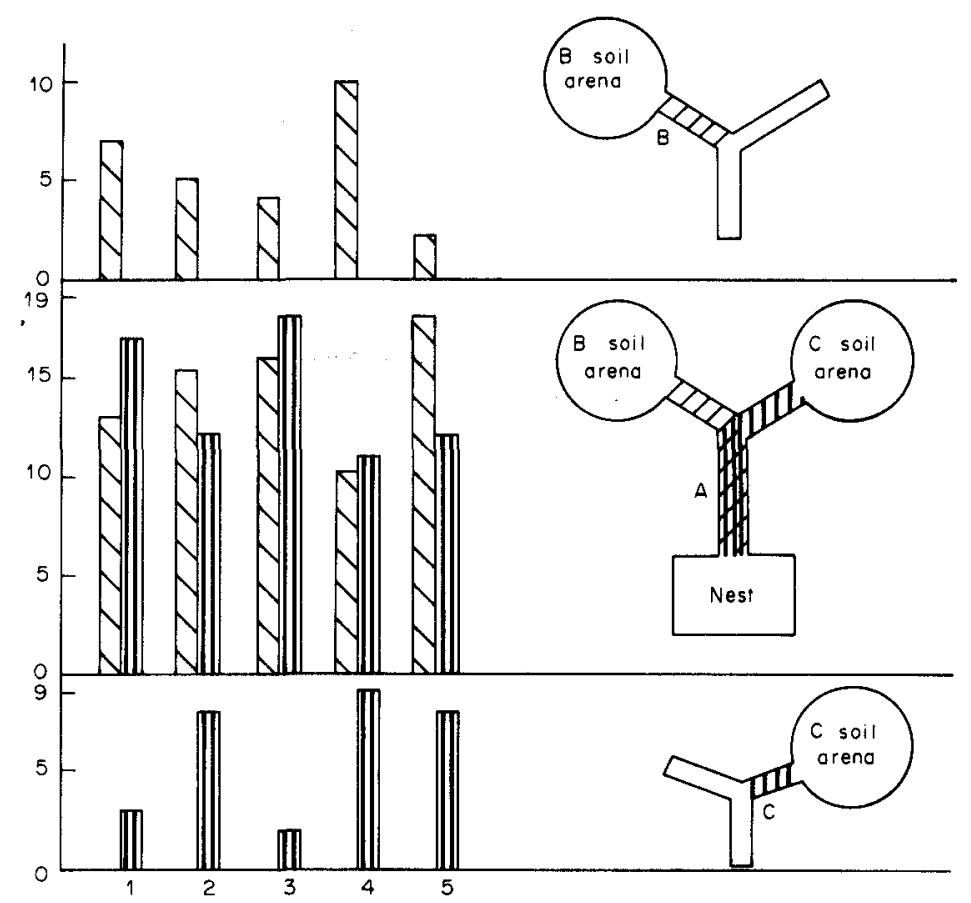

Fig. 10. Histograms showing the results obtained from bioassays of natural trails laid by termites moving from nest through the Y-stem A, and through either of the two branches (B or C) to either of the two soil arenas (e.g. soil $\mathrm{B}$, or soil $\mathrm{C}$, arena).

the graphs (Fig. 9a and b) can be summarized as follows: when the two arenas contained only soil, the tests of trail of the passing termites through B and C did not give any significant difference [see Fig. 9a, (i)

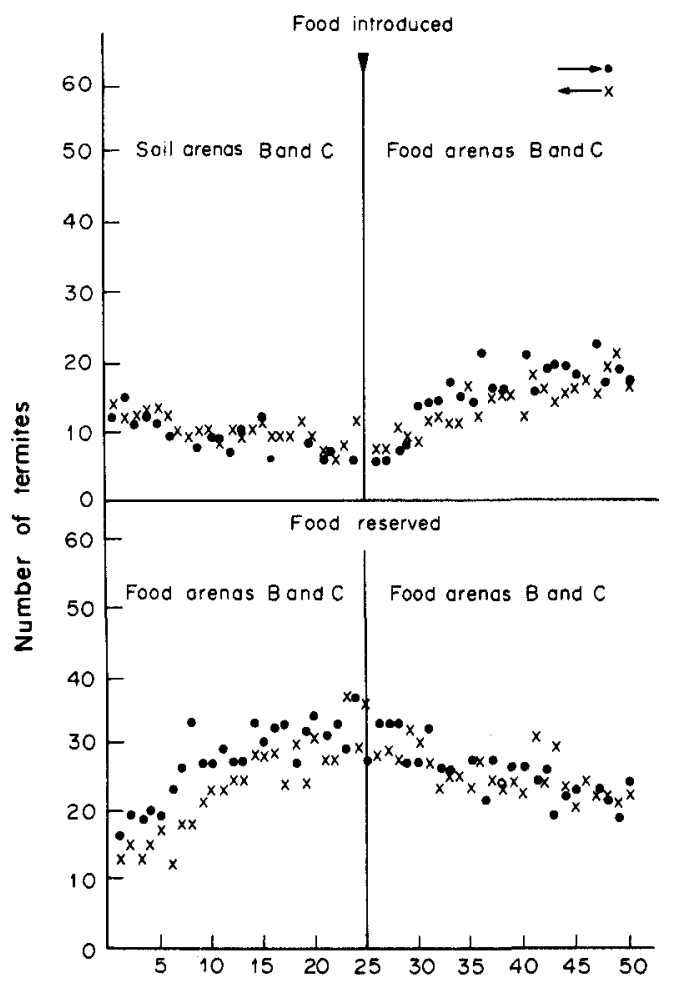

Fig. 11. Illustration of recruitment/traffic regulation in relation of newly supplied food source (arena) when food is removed from old source (arena). and (ii)]. When food was introduced to $\mathrm{B}$ arena and plastic was introduced to $C$ arena, comparative trail following tests between $B$ and $C$ gave significant preference for the food side B [Fig. $9 \mathrm{~b}$ (i) and b (ii)]. This experiment showed that there was continuous trail information on the substrate along the entire B and $\mathrm{C}$ channels. It is a possibility that even the unexperienced workers decide towards the food side by trail information on the substrate of the forking. Here it is necessary to carry out trail test with unexperienced workers, to confirm this assumption.

Trail strength in relation to the number of passing termites

Experiment without food in $B$ and $C$ arenas. In this experiment, a $Y$-channel was connected with rubber tubing from nest (A) to two soil arenas (b and c). At the three arms of the $Y$, three trail collecting bridges were connected respectively, in each of which trail collecting paper slip was placed. Termites were allowed to walk on these paper slips in the bridges for $1 \mathrm{hr}$. After this, each of the two halves of trail A was tested with equivalent lengths of trails $B$ and $C$, respectively. The results, as demonstrated on histograms (see Fig. 10) showed that trail A was significantly stronger than either trails B or C. These results confirmed that exploratory trail activity is positively influenced by the walking frequency.

\section{EXPERIMENTS ON TRAFFIC REGULATION IN RELATION TO NEWLY SUPPLIED FOOD: EFFECT OF FOOD VERSUS NO FOOD}

In this experiment the set up was similar to that in the earlier recruitment experiment.

Recording in this experiment started when the 


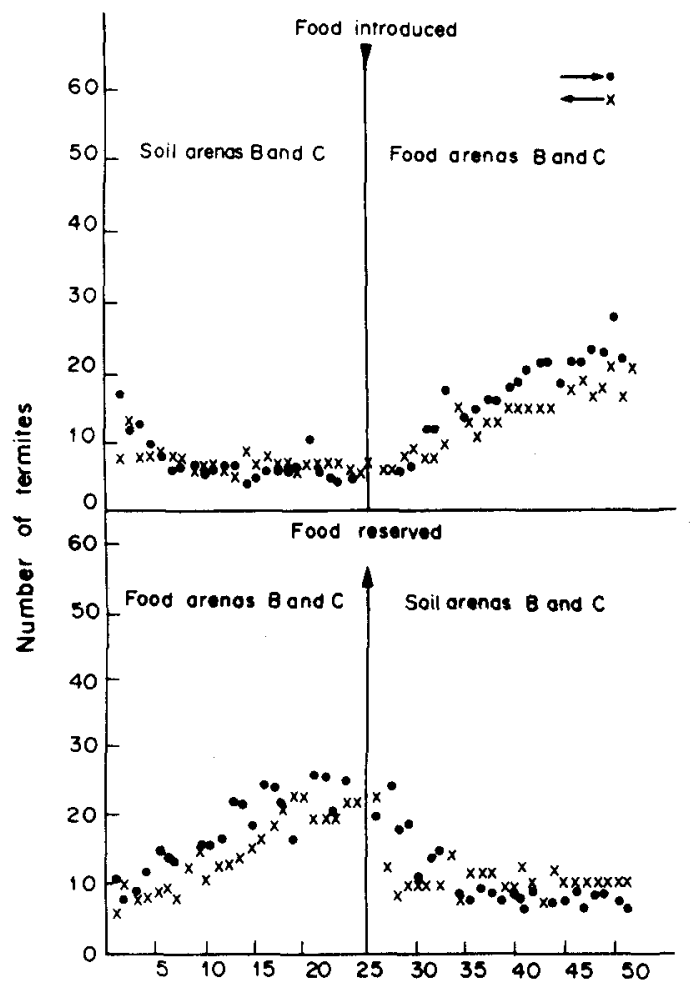

Fig. 12. Illustration of recruitment/traffic regulation in relation to newly supplied food source (arena), when food was still left in the old food source (arena).

termites had started running normally to and from the two soil arenas. After recording for a couple of minutes, food was lowered to one arena (say B). After recording for another $25 \mathrm{~min}$, food was raised from arena $\mathbf{B}$, and simultaneously, food was lowered to arena $C$, without anỳ disturbance. Recording continued for another $25 \mathrm{~min}$. The experiment was replicated six times.

The results from this experiment revealed that there was rapid communication of the presence of food in the arena within 3-4 min (see Fig. 11). The results further supported the evidence of a recruitment trail which was maintained through trail reinforcement by the passing termites. The results also showed that this recruitment trail was highly volatile or denatured, because the presence or absence was noticed within 3-4 min, through rise or drop in traffic when food was introduced or removed from the arena. The termites probably laid ordinary foraging trail at the time when there was no food in the arena (see Figs 11 and 12)

EFFECT OF NEWLY FOUND FOOD SOURCE, SUPPLIED IN ADDITION TO THE ALREADY EXISTING FOOD SOURCE (COMPETITIVE SITUATION)

This experiment was set up to find out if there is any traffic diversion if a new food source is discovered by stray foragers even with already existing food source for the colony.

In this experiment, after recording for a couple of minutes to the two soil arenas, food was lowered to arena B, for example. After recording for $25 \mathrm{~min}$, without stopping the recording, food was lowered to arena $C$ (without removing the food from the arena B). Recording continued for another $25 \mathrm{~min}$. The experiment was replicated six times.

The results showed that the trails to newly found food did not become significantly dominant over the trail to the already existing one, but rather it became equivalent to it (see Fig. 12).

\section{Comprehensive analysis of traffic development in} relation to food supply

Using the newly devised double-bridge experiment (see Figs 4 and 6) a comprehensive analysis of traffic development in relation to food supply was made. It was confirmed that food initiated increased traillaying by higher percentage of returners than the outgoers (see Fig. 13) From the results it was possible to suggest that food-carrying and the recruitment trail, recruited more termites from the nest as well as stimulated the termites to move to the food source. It was also observed that the presence of food accelerated building activity in this species of termites (see Figs 13 and 14).

As already observed by Malaka (1980b) and confirmed by this study the workers of $A$. evuncifer often carry mound materials for building their runways (galleries) on their outward journeys from the nest to the arena. It was generally observed that when termites (workers) deposited the mound materials they were carrying (with their mandibles beside the foraging track), they turned to return to their nest rather than continue their journey to the arena.

This action is an indication that the termites have a sense of direction to and from the nest, when they move between their nest and the arena. Also a termite (worker) returning from the arena was observed seizing nest material from a nest mate (worker) coming from the nest, and after this, the robbed nest mate immediately turned back to return to the nest. As it was stated earlier, generally, nest materials were conveyed by the termites from the nest, although in very few cases they have been observed to carry nest materials from the arena (see Figs 15 and 16).

\section{Analysis of strong trail laying (STL) activity and food carrying population of the returners}

During the first $25 \mathrm{~min}$ of the experiment when only soil was in arena $\mathrm{C}$, the number of returning workers laying strong trails fluctuated within zero to two termites per min. During the next $25 \mathrm{~min}$ when food was introduced to arena $\mathrm{C}$, the strong traillaying returners fluctuated within zero and six termites per min. During this time also when food was introduced to arena $C$, the returning workers carrying food pieces in their mandibles, fluctuated within 0-16 termites per min (Fig. 17 for detailed results).

From the results (see Fig. 17) it seemed that food carrying by the returning workers (from the food arena), acted also as a regulatory mechanism in recruitment activity. It may be stated that food carrying (of returners), as well as recruitment trail laid by some returners attracted the termites to orient to the food source (at the Y-junction). This fact will be confirmed by future experiments. 


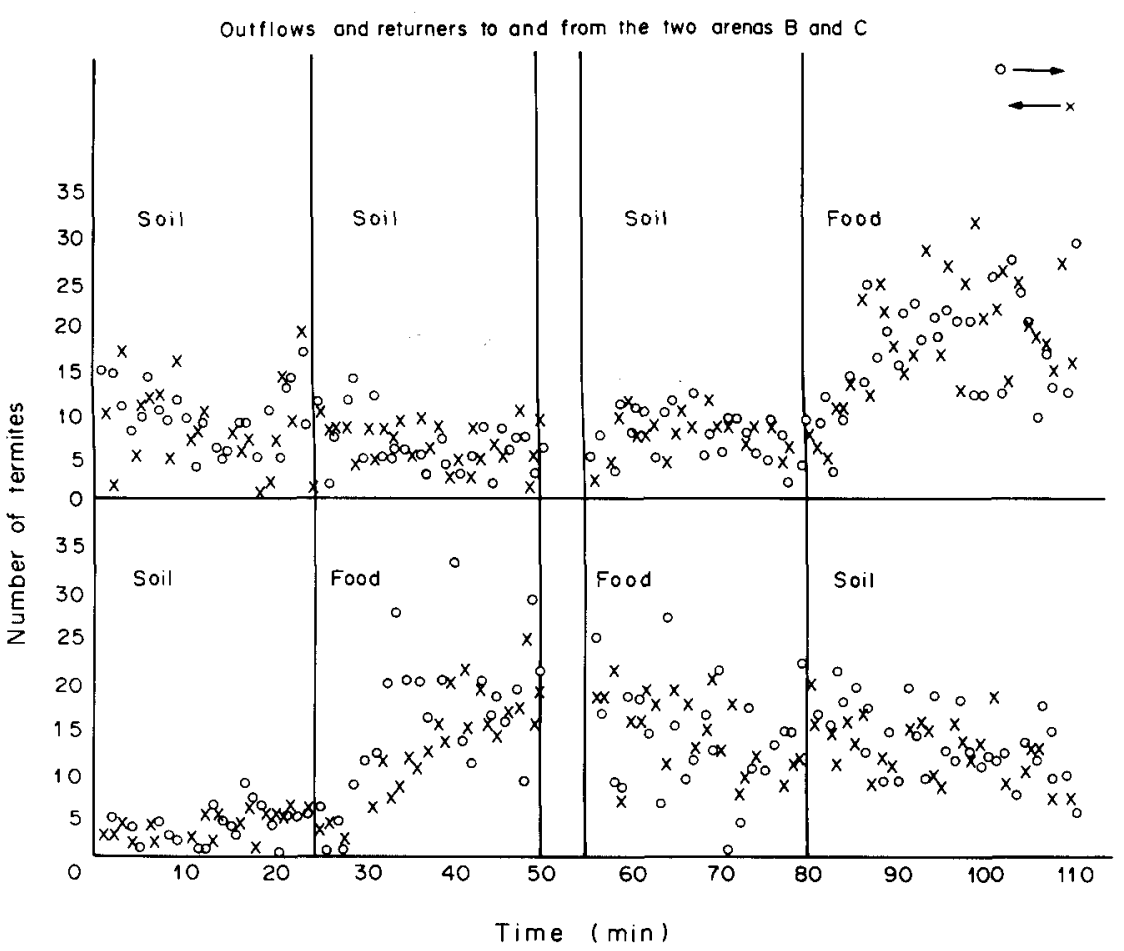

Fig. 13. Illustration of comprehensive analysis of recruitment/traffic in relation to ' food supply (with double-bridge).

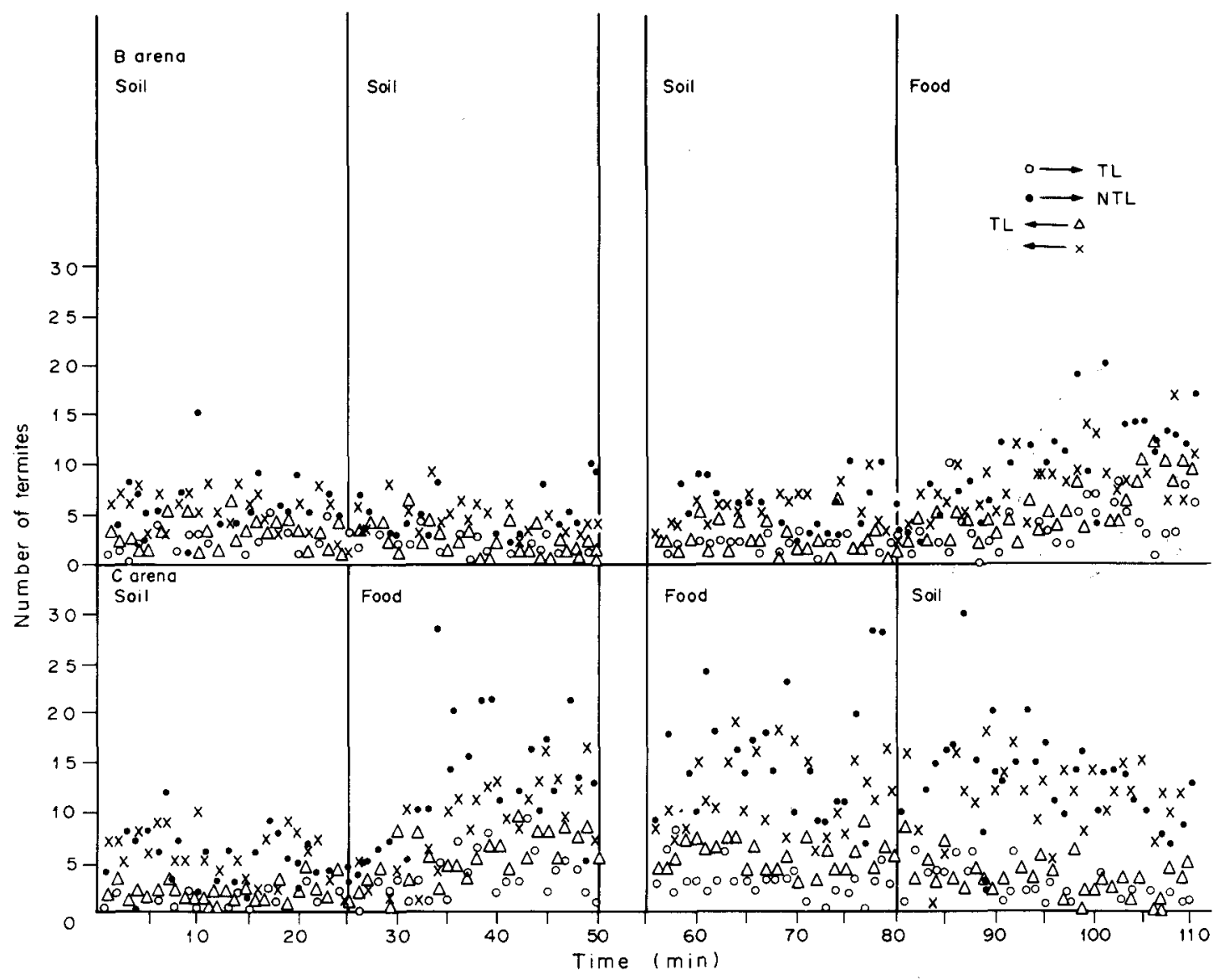

Fig. 14. Illustration of comprehensive analysis of trail-layers and non-trail-layers to and from the arenas, before and after food supply and after food reversal (with the double-bridge). 


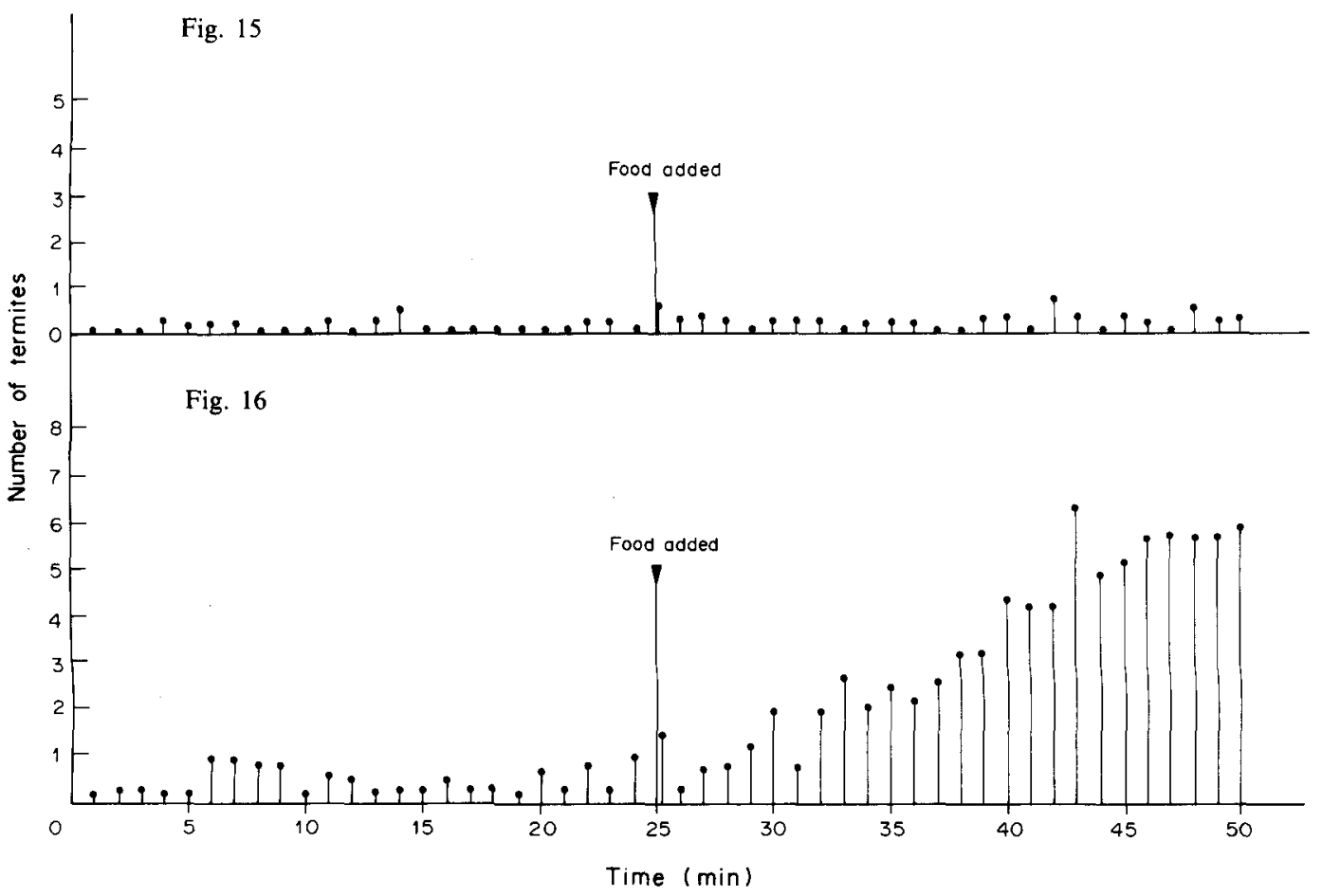

Fig. 15. Showing the average number of workers mean of six experiments of Amitermes evuncifer conveying mound material (soil) from arena to the nest before and after food supply.

Fig. 16. Showing the average number of out-going workers mean of six experiments of Amitermes evuncifer conveying mound material (soil) from nest to arena (before and after food supply).

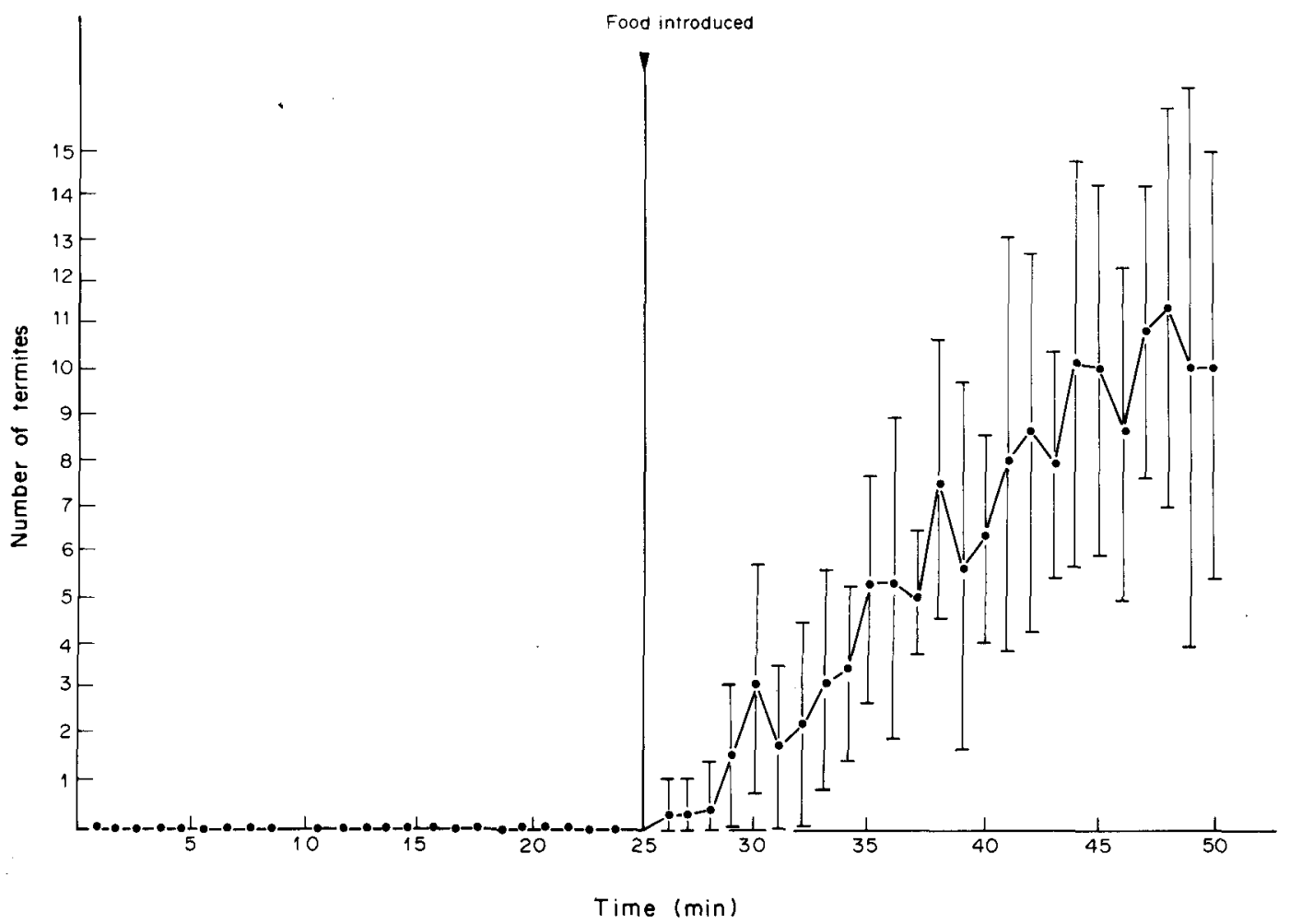

Fig. 17. Showing the average number of homing workers (mean of six experiments) of Amitermes evuncifer conveying food from the arena to the nest (after food supply). 


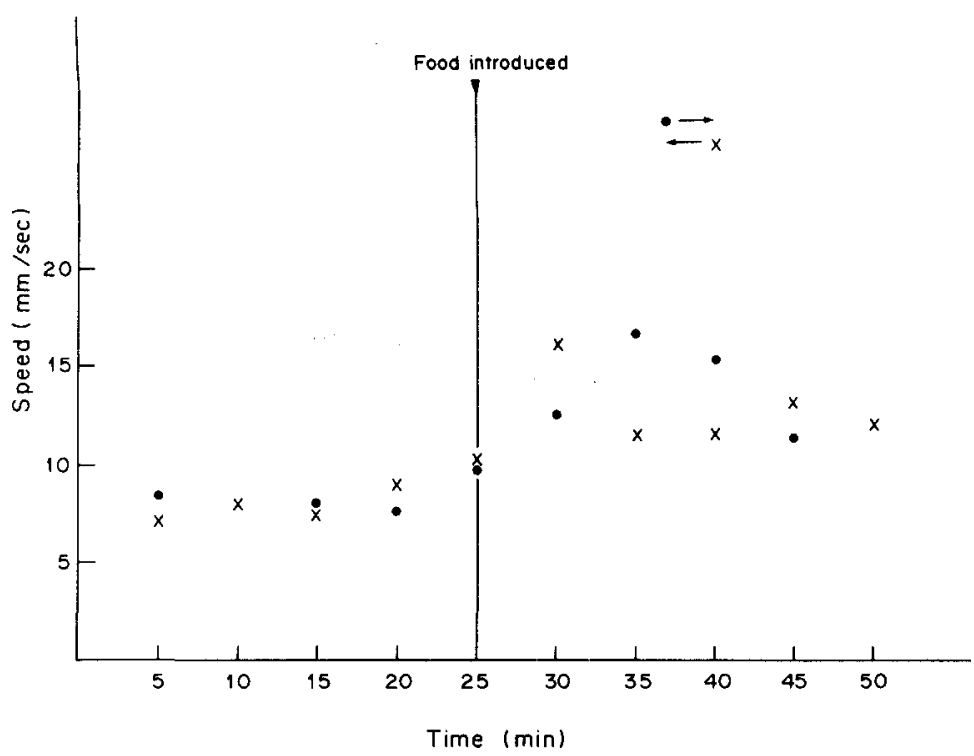

Fig. 18. Graph (average of six experiments) showing the running speed (in $\mathrm{mm} / \mathrm{sec}$ ) of Amitermes evuncifer from and to arena, before and after food supply.

\section{SPEED (in $\mathrm{mm} / \mathrm{sec}$ ) OF TERMITES BETWEEN NEST AND ARENA}

During the first 25 min when only soil was in arena $\mathrm{C}$, the average speed of the outgoers fluctuated between 6.6 and $9.8 \mathrm{~mm} / \mathrm{sec}$. During the next $25 \mathrm{~min}$, when food was introduced in arena $C$, the speed of the outgoers fluctuated between 11.2 and $16.6 \mathrm{~mm} /$ sec (see Fig. 18). From these results, it is quite clear that the running speed of termites (of both outgoers and returners) is higher when there was food than when there was no food in the arena (see Fig. 18). This increase in running speed when food was introduced is in conformity with the rapid communication of the presence of food in the arena within $3.4 \mathrm{~min}$ as already observed in earlier experiments (Fig. 18). The fact that, within the first $5 \mathrm{~min}$ when food was introduced the speed of returners $(16 \mathrm{~mm} / \mathrm{sec})$, was higher than the speed of the outgoers $(12.5 \mathrm{~mm} / \mathrm{sec})$, indicates that the experienced returners actually communicated the presence of food to their nest mates (see Fig. 18). This is also due to the fact that the fast running speed of the initial returners is responded to soon afterwards by subsequent outgoers whose population increased progressively until an optimum number (or traffic) must have been reached.

It may thus be concluded from the study, that the recruitment activities in Amitermes evuncifer entail;

(1) Strong (recruitment) trail.

(2) Fast running speed of experienced returning workers.

(3) Oscillatory movements of returning workers.

The stimuli which enables the recruited termites to make correct orientation to the food side include:

(1) Strong trail.

(2) Higher speed.

(3) Food carrying by some returning workers.

(4) Oscillatory movements.

The responses of the (newly) recruited workers to the recruitment/orientational activities of the experienced returners entail:

(1) Higher running speed.

(2) Strong trail-laying.

(3) A higher number carrying mound material for building galleries.

(4) Correct orientation by a greater number of outgoers, to the food side.

(5) Oscillatory movements are also performed by some of them.

\section{Trail test of up to 5 min after food supply}

It has been confirmed that, in the laboratory colony of Amitermes evuncifer, there is rapid communication of the presence or absence of food in the arena within 3-4 min. Trail pheromones have been implicated as one of the regulatory factors in the communication systems of this termite species. It was important to determine whether stronger trails were already established on the food side within the initial 5 min after food was introduced to the arena. This was possible by carrying out a comparative trail bioassay between food and soil arenas, up to $5 \mathrm{~min}$ after food supply. The results confirm how much trails are implicated in the rapid communication of food presence within the colony.

In this experiment, trail-collecting paper slips were introduced in the two bridges attached to the channels leading to the two initial soil arenas (i.e. arenas $B$ and $C$ ). After the termites were allowed to run between the nest and the two soil arenas for $25 \mathrm{~min}$, food was introduced to one of the arenas. The termites were then allowed to run for another $5 \mathrm{~min}$ (i.e. after the food supply to one of the arenas), and the trail paper slips were then taken out of the food and the soil channels. A comparative trail bioassay of the two paper slips was carried out. Ten replications of the experiment was carried out as can be seen from the results. For each trail bioassay, six termite runs were carried out (see Table 1). 
Table 1. Results obtained from tests of trails collected up to $5 \mathrm{~min}$ after food supply

\begin{tabular}{cc}
\hline $\begin{array}{c}\text { Trail paper from } \\
\text { food channel }\end{array}$ & $\begin{array}{c}\text { Trail paper from } \\
\text { soil channel }\end{array}$ \\
\hline 4 & 2 \\
6 & 0 \\
5 & 1 \\
4 & 2 \\
4 & 2 \\
3 & 2 \\
5 & 1 \\
3 & 3 \\
6 & 0 \\
Total 43 & 17 \\
\hline
\end{tabular}

These results show that the trails to the food arena were significantly more active than those to the soil arena (at $P=0.05$; see Table 1).

From the results, it can be concluded that trail strength on the food channel is already more on the food side than on soil side, $5 \mathrm{~min}$ after food supply. The results confirm the overriding influence of trail pheromone at the initial recruitments in the colony of Amitermes evuncifer.

\section{DISCUSSION}

Recruitment involves the gathering together of nest mates at a particular place for purposes of applying a joint effort to a specific task, such as nest construction and food retrieval (Atkins, 1980). In this study, from the experimental set up, devised for the purpose, it was possible to prove that a colony of Amitermes evuncifer exhibits quantitative recruitment to food source. This hypothesis has never been proven for this species of termites. It is quite clear now that recruitment can be said to have taken place in the relevant experiment, because the traffic population rose significantly, and also a temporary excess of outgoers was never compensated by a negative excess of returners (see Fig. 8a, b and c). The fact that the ratio of traffic changed towards the food side in a choice situation (i.e. between food and non-food arenas), demonstrated that there was spatial information for the orientation towards the food side (Fig. 8 $\mathrm{d}$ and e). So far mostly workers (with some few accompanying soldiers) were involved in recruitment activities in Amitermes evuncifer. It is common knowledge that in most social insects, the worker caste acts as scouts and recruiters of their nest mates (or confederates) to sources of food (or reward). The protective value of the soldier caste during recruitment exercise is exhibited by the accompanying soldier of Amitermes evuncifer, whose recruitment activities are carried out by mostly the worker caste (Malaka, 1980b).

From the comparative trail bioassay between food and non-food sources (e.g. arenas) it was found that trail pheromone concentration was dominant on the food side (see Fig. 9). It was also observed that the direction of trail was possibly registered by the termites. This conclusion was based on the observation that picked-up soil particles were generally carried in distal direction (i.e. from nest to arenas) on the trail. Jander and Daumer (1974) found that the odour trails laid down by the foraging columns of Hospitalitermes are bidirectional. And that misdirected homing termites restore their correct orientation after a series of head-on collisions with correctly oriented companies. Jander and Daumer (1974) concluded that no outside directional stimuli in particular (e.g. light and gravity) are used by Hospitalitermes to make up for the directional ambivalence of the odour trail. However, Butler (1967) observed that when a wandering ant finds a trail along which ants are running in both directions, she can probably tell in which direction to run to reach either the nest or the food, because most home-returning ants will be carrying booty (food), whereas those running towards the food will have none. From this study, home-returning foragers of Amitermes evuncifer were observed carrying food from food sources (food arena) to their nest. The food carrying home-bound workers possibly make up for the directional ambivalence of the recruitment trail. Oloo (1979) stated that unlike social Hymenoptera which utilize visual as well as chemical cues, the blind foraging termites rely almost entirely on chemical signals for orientation outside the nest throughout foraging activity.

From observations it may be suggested that in Amitermes evuncifer both pheromonal trail and mechanical displays are implicated in recruitment to food source. This impression was also communicated by Oloo and Leuthold (1979) in Trinervitermes bettonianus. These are comparable to mechanisms utilized by ants (Leuthold, 1968; Holldobler, 1971; Szlep-Fessel, 1970; Moglich and Holldobler, 1975).

In the study of traffic regulation in relation to newly supplied food, it was possible to observe the rapid communication of the presence of food in the arena within 3-4 min. This phenomenon supports the case for a feed-back effect or of biological equilibrium. This meant that, whenever food supply was observed (between food and non-food arena), fewer returners from the new food source (arena), laid more trails than the initial larger number of returners from the now non-food arena (i.e. previous food source). Jaffe and Howse (1979) showed that the amount of recruitment produced by the colony of Atta cephalotes $(\mathrm{L})$ is independent of the number of ants initially returning to the nest from a newly discovered food source. The results further support the evidence of a recruitment trail which is maintained by trail reinforcement by passing termites (through their regulatory mechanisms) as long as food is present in the arena. The results also showed that this recruitment trail was highly volatile (or quickly denatured), because the presence or absence was observed within 3-4 min, through rise or drop in traffic population when food was introduced in the arena, or when food was removed from the arena. The termites therefore probably laid (or reinforced) ordinary foraging trail at the time when there was no food. These results are confirmed by the recent findings of Traniello (1981, 1982) who reported that the trail pheromone of Nasutitermes costalis is characterized by an ephemeral component that regulates recruitment and an incredibly persistent substance that provides a longlasting orientation cue. Traniello, further concluded that the recruitment effect, although strong at first, decayed rapidly within $10 \mathrm{~min}$. Oloo and Leuthold 
(1979) found that in a laboratory foraging situation food, when detected, stimulates workers of Trinervitermes bettonianus (Sjost) to lay stronger recruitment trails and to motivate nest mates to mass foraging. They also found that two to ten rewarded workers were capable of motivating a significant number of nest mates to foraging.

From another related experiment with A. evuncifer, it was found that newly found food (of the same kind) did not become more dominant (in effect) than the already existing food, but rather, it became equivalent to the other earlier supplied food. This showed that the strong recruitment trail to the original food source (arena) was maintained by trail reinforcement, and did not become weaker than the newly developed recruitment trail to the newly discovered food source. These conclusions were confirmed by the finding that termite traffic population was almost equally shared between the two food sources (i.e. arenas B and C). It was possible that apart from the trails, the termites used some other regulatory mechanisms to communicate food information to their confederates.

According to Malaka (unpublished material) the strong trail-laying position (STL) is when the ventral surface of the abdomen up to the portion of the sternal gland, was tightly pressed against the substratum. The weak trail-laying position (WTL) is when the ventral part of the abdomen was slightly pressed against the substratum. When the termites were in non-trail-laying position (NTL), the abdomen was raised from the substratum. The termites were observed laying trails in both directions, between the nest and the arena. These findings are in conformity with the results obtained from a comprehensive analysis of traffic development in relation to food supply (with the double-bridge experiment). When food was added to the soil arena, the following activities were observed.

(1) A higher population of the returning workers (from the current food arena) laid more trails than that of the outgoing workers (see Fig. 14).

(2) The non-trail laying outgoing workers were significantly higher in number than the non-trail laying returners.

(3) A greater number of the returners laid strong trails (STL) than the outgoers, comparatively.

This phenomenon may be different for different termite species. According to McFarlane (1981) the presence or absence of food in the foraging arena seemed not to influence trail laying behaviour in Macrotermes michaelseni, and there was no evidence for recruitment trails under the experimental condition. Howard et al. (1976) stated that the stimuli which elicit trail pheromone deposition are basically unknown and may vary for each species.

On the other hand Butler (1967) found that the intensity of an odour trail and its attraction to potential foragers vary with the amount and quality of the food supply. It is quite clear that in several ant species, scouts initially use visual orientation to randomly search for food independently; the rewarded scout then communicates the discovered food by laying pheromonal trail from the source to the nest (Carthy, 1951; Wilson, 1965; Leuthold, 1968; Szlep-
Fessel, 1970; Holldobler, 1971, 1976; Moglich and Holldobler, 1975; Jaffe and Howse, 1979).

(4) The number of food-carrying-returning workers increased progressively (see Fig. 17). From observations, it was likely that food-carrying also acted as a regulatory mechanism in recruitment/orientation. In fact, there was a possibility that food-carrying (of returners), as well as recruitment trails laid by experienced returners, attracted the termites to orientate correctly to the food sources.

(5) The number of outgoers carrying nest material (for building) increased significantly (see Fig. 16). This indicates that the presence of food (in the arena) accelerates building activity in this species of termites. But the number of returners carrying nest material to the nest before and after food supply was very insignificant (see Fig. 15).

(6) The significant increase in total traffic when food was reversed indicated a novelty effect of the new food source on Amitermes evuncifer (particularly when the new food source was provided and old food source was removed; see Fig. 11).

(7) Also from available data (see Fig. 18), it was quite clear that the termites moved faster after food was introduced in the arena, than when there was only soil in the arena. After a closer look at the results, it is possible to conclude that the speed is also a regulatory factor in recruitment/orientation as well as a response to trail strength. McFarlane (1981) found that traffic speeds up in Macrotermes michaelseni as the trail strength increases. Szlep-Fessel (1970) found that the recruiting Pheidole returning from an attractive bait runs at higher speed than normal towards the nest.

Acknowledgements - The authors wish to thank the following: the Swiss Authorities for granting a stipendium to the senior author; the University of Berne for providing the facilities; the University of Lagos for research grant and study leave to the senior author; the late professor $M$. Luscher (may his soul rest in perfect peace), who recommended the senior author to the Swiss Authorities; and all our colleagues in the termite group in the University of Berne. This work is part of the Ph.D thesis submitted to the University of Lagos by the senior author.

Grateful thanks are due to Professor E. N. Kwofie of the Department of Modern European Languages, University of Lagos for the French translation.

\section{REFERENCES}

Atkins M. D. (1980) Introduction to Insect Behaviour. Macmillan, New York.

Blum M. S. and Ross G. N. (1965) Chemical releasers of social behaviour V. Source, specificity and properties of odour trail pheromone of Tetramorium guineense $\mathrm{F}$. J. Insect Physiol. 11, 857-868.

Butler C. F. (1967) Insect pheromones. Biol. Rev. 42, 42-87. Carthy J. D. (1951) The orientation of two allied species of British ants II; Odour trail laying and following in Acanthomyops (Lasius) fuliginosus. Behaviour 3, 304-318.

Hangartner W. (1969) Trail laying in the subterranean ant Acanthomyops interjectus. J. Insect Physiol. 15, 1-4.

Holldobler B. (1971) Recruitment behaviour in Camponotus sociux (Hym. Formicidae), Z. vergl. Physiol. 75, 123-142.

Holldobler B. (1976) Recruitment behaviour, home range orientation and territoriality in harvester ants Pogonomyrmex. Behav. Ecol. Socio-biol. 1, 3-44.

Howard R., Matsumura F. and Coppel H. C. (1976) Trail following pheromones of the Rhinotermitidae: 
approaches to their authentication and specificity. $J$. chem. Ecol. 2, 147-166.

Jaffe K. and Howse P. E. (1979) The mass communication system of the leaf cutting ant, Atta cephalotes (L.). Anim. Behav. 227, 930-939.

Jander R. and Daumer K. (1974) Guideline and gravity orientation of blind termites foraging in the open (Termitidae: Macrotermes, Hospitalitermes). Insectes soc. 21, $45-69$.

Leuthold R. H. (1968) Recruitment to food by the ant Crematogaster ashmeadi. Psyche 75, 334-350.

Malaka S. L. O. (1973) Observations on termites in Nigeria. Nigeria Field 38, 24-40.

Malaka S. L. O. (1977a) A study of the chemistry and hydraulic conductivity of mound material and soils from different habitats of some Nigerian termites. Aust. J. Soil Res. 15, 87-91.

Malaka S. L. O. (1977b) A note on bulk density of termite mounds. Aust. J. Soil Res. 15, 93-94.

Malaka S. L. O. (1977c) Temperature studies of the mound and environment of Amitermes evuncifer Silvestri (Isoptera: Termitidae). Aust. J. Zool. 25, 711-719.

Malaka S. L. O. (1980a) The reaction of Amitermes evuncifer Silvestri (Isoptera:Termitidae: Amitermitinae) towards the bodies of different insect species and their extracts. J. nat. Hist. 14, 339-350.

Malaka S. L. O. (1980b) Foraging behaviour of Amitermes evuncifer Silvestri (Isoptera:Termitidae:Amitermitinae). J. nat. Hist. 14, 351-361.

Malaka S. L. O. (1983) Economic importance of termites; six case studies in Nigeria and Ghana. Nigeria Field 47, 222-230.

McFarlane J. (1981) Observations on sternal gland trail pheromone, trail laying and longevity of natural trails in the termite Macrotermes michaelseni. Unpublished report.
Moglich M. and Holldobler B. (1975) Communication and orientation during foraging and emigration in the ant Formica fusca. J. comp. Physiol. 101, 275-288.

Oloo G. W. (1979) Specificity of pheromonal trail in Trinervitermes bettonianus. ICIPE Publication No. 78 , pp. 30 32.

Oloo G. W. and Leuthold R. H. (1979) The influence of food on trail laying and recruitment behaviour in Trinervitermes bettonianus (Termitidae:Nasutitermitinae). Entomologia exp. appl. 26, 267-278.

Sands W. A. (1962) Observations of termites destructive to tree and crops in Nigeria. North. Reg. Min. Agric. Samaru Res. Bull. 26, 1-14.

Sands W. A. (1971) Termites as pests of tropical food crops. A paper presented at a seminar on Agricultural Research in West Africa. Sponsored by IITA at Conference Centre, University of Ibadan.

Szlep-Fessel R. (1970) The regulatory mechanism in mass foraging and the recruitment of soldiers of Pheidole. Insectes soc. 17, 233-244.

Traniello J. F. A. (1981) Enemy deterrence in the recruitment strategy of a termite: soldier organized foraging in Nasutitermes costalis. Proc. natn. Acad. Sci. U.S.A. 78, 1978-1979.

Traniello J. F. A. (1982) Recruitment and orientation components in a termite trial pheromone. Naturwissenschaften 69, 343-345.

Wilson E. O. (1962) Chemical communication among workers of the ant Solenopsis saevissima (Fr. Smith) 1. The organization of mass foraging. Anim. Behav. 10, 134-147.

Wilson E. O. (1965) Chemical communication in social insects. Science 149, 1064-1071.

Wilson E. O. (1971) The Insect Society. Belknap Press, Cambridge, Mass. 